IP Periodica Polytechnica Electrical Engineering and Computer Science

60(2), pp. 125-134, 2016

DOI: $10.3311 /$ PPee. 8953

Creative Commons Attribution (1)

RESEARCH ARTICLE

\section{Performance Analysis of Multi Functional VSC Based FACTS Devices in Power Flow Management}

\author{
Velamuri Suresh $^{1 *}$, Sreejith Sekharan ${ }^{2}$
}

Received 29 December 2015; accepted 22 February 2016

\begin{abstract}
This paper illustrates the application of Voltage Source Converter (VSC) based Flexible AC Transmission systems (FACTS) controllers such as Static shunt Compensator (STATCOM) and Unified Power Flow Controller (UPFC) for power flow control. A unique modelling framework incorporating these FACTS controllers in Newton Raphson load flow solution is discussed. The effectiveness of both the devices for real power flows, power loss, reactive power injection and voltage profile improvement are analysed. The modes of operation of each device with respect to specified voltage are analysed. The performance of these devices under single line contingency is also discussed. Test results on standard 5 bus system and IEEE 30 bus test system are analysed which justifies the potency of these devices for the above said applications.
\end{abstract}

\section{Keywords}

FACTS, STATCOM, UPFC, VSC, power flow, contingency

${ }^{1}$ School of Electrical Engineering, VIT University,

Katpadi road, Vellore, India

"Corresponding author, e-mail: velamuri.suresh@vit.ac.in

\section{Introduction}

Deregulation of power industry and uneven distribution of load centres over the system leads to unsteady power flows in the lines. Certain lines are underutilized and some of them are over loaded [1]. Problems like voltage instability, power loss, power oscillations, reactive power consumption causes the existing power system insecure [2]. These problems require upgradation of existing power network. To concentrate on the existing problems of power system the important step is to conduct the steady state analysis [3].

Power flow analysis is an essential step for evaluation of a power system under steady state conditions. It is also useful for future expansion with respect to continuous growth of system demand. Many power system problems such as economic dispatch, optimal power flow and unit commitment can't be performed without this analysis. The basic outcome of this analysis is voltage profile, power flows in the lines, Losses and phase angles at various nodes of the test system. Based on these studies necessary corrective action can be taken to maintain the power system in a secure condition.

In the existing transmission system certain constraints like voltage instability, fault levels, poor power sharing in parallel circuits, congestion and many others influence the circuit utilisation capability. To overcome these problems and allow the lines operate at their thermal rating Flexible AC Transmission Systems (FACTS) technology is a compromising solution [4]. FACTS controllers are basically power electronic devices which automatically control the parameters like line impedance, bus voltage and phase angle of the network [5]. FACTS controllers are classified as Series, Shunt, Combined series-shunt devices based on their existence in the system [4]. Reactive power management is needed to enhance the standard of power supply in ac power systems to possess higher utilization of existing equipment leading to the deferment of latest investment for equipments and transmission lines [6]. By using the shunt FACTS controllers reactive power management is best done and thus improving voltage profile of the system. Series FACTS controllers helps in improving power flows in the lines [7]. 
There are two generations of FACTS controllers, of which the first generation devices are based on convectional thyristor switched capacitors and reactors. The devices coming under this category are Static Var Compensator (SVC), Thyristor Controlled Series Capacitor (TCSC), Thyristor Controlled Phase Shifter (TCPS). The second generation devices employs Voltage Sourced Converters. Devices coming under this category are Static shunt Compensator (STATCOM), Static Synchronous series Compensator (SSSC), Interline Power flow Controller (IPFC), Unified Power Flow Controller (UPFC) [8].

FACTS devices are modelled for power flows and incorporated in existing power flow. In [9] UPFC is modelled as a series reactance along with power injections made at the end of the reactance. In this model the voltage magnitude and phase angle must be manually adjusted so as to go with the intended power flow. In [10] a very simple model of UPFC is presented which works only when the control parameters voltage magnitude and power flows are controlled concurrently. In [11-12] FACTS controllers are modelled such that they are easily incorporated in the existing Newton Raphson power flow by modifying the Jacobian matrix. The advantages of this method are getting a robust iterative solution which converges very quickly and the parameters are independently controlled.

In this paper, case studies are carried out to analyse the performance of FACTS devices during variable loading and contingency conditions. The performance of FACTS devices to improve the transmission line voltage is also analysed. FACTS controllers are modelled to incorporate them in to the existing load flow and their parameters are tuned according to the requirement. The ability of FACTS controllers for maintaining desired voltage and power flows under normal and contingency conditions is demonstrated. Two FACTS controllers namely STATCOM and UPFC are incorporated in the existing Newton Raphson power flow and the following cases are analysed on standard 5 bus test system and IEEE 30 bus system.

a) Analysis of FACTS devices under Base Load condition.

b) Operating Modes of FACTS devices corresponding to specified voltage.

c) Analysis of FACTS devices under increased Loading condition.

d) Analysis of FACTS devices under single line contingency.

\section{Modelling of FACTS Devices}

FACTS devices are modelled as state variables and incorporated in the actual load flow. The detailed modelling and the corresponding equations are discussed in this section.

\subsection{Modelling of STATCOM}

STATCOM comprises of series connection of voltage sourced converter (VSC) and a tap changing transformer whose primary is connected in shunt with the ac system [13]. The circuit diagram of STATCOM is shown in Fig. 1. STATCOM is represented by a synchronous voltage source with maximum and minimum voltage limits. The equivalent circuit shown in Fig. 2 is used to derive the mathematical model of the controller for inclusion in power flow algorithm [14].

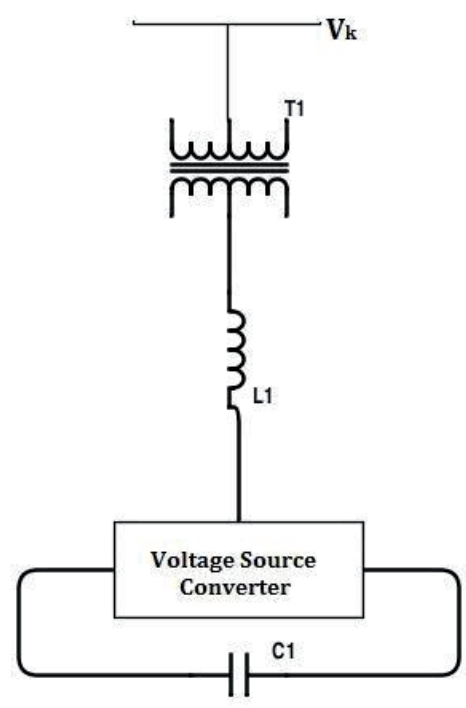

Fig. 1 Basic structure of STATCOM

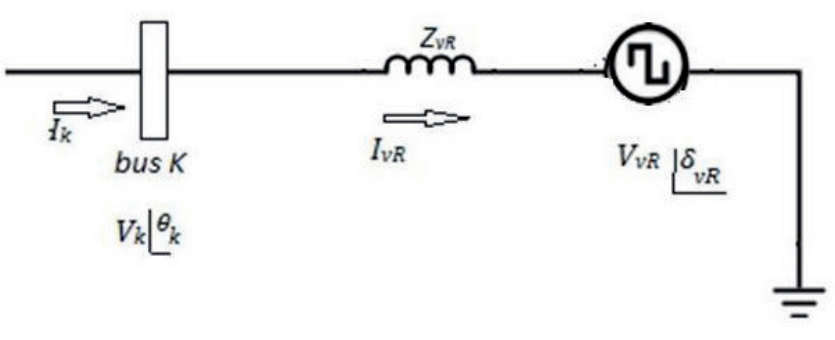

Fig. 2 Equivalent circuit of STATCOM

\subsubsection{Power flow equations of STATCOM}

The STATCOM voltage source equation given with respect to Fig. 2 is

$$
E_{v R}=V_{v R}\left(\cos \delta_{v R}+j \sin \delta_{v R}\right)
$$

Consider that STATCOM is connected at bus k. From Fig. 2 the active and reactive power equations at the converter and bus $\mathrm{k}$ are [15]

$$
\begin{aligned}
& P_{v R}=V_{v R}^{2} G_{v R}+V_{v R} V_{k}\left[G_{v R} \cos \left(\delta_{v R}-\theta_{k}\right)+B_{v R} \sin \left(\delta_{v R}-\theta_{k}\right)\right] \\
& Q_{v R}=-V_{v R}^{2} B_{v R}+V_{v R} V_{k}\left[G_{v R} \sin \left(\delta_{v R}-\theta_{k}\right)-B_{v R} \cos \left(\delta_{v R}-\theta_{k}\right)\right] \\
& P_{k}=V_{k}^{2} G_{v R}+V_{k} V_{v R}\left[G_{v R} \cos \left(\theta_{k}-\delta_{v R}\right)+B_{v R} \sin \left(\theta_{k}-\delta_{v R}\right)\right] \\
& Q k=-V_{k}^{2} B_{v R}+V_{k} V_{v R}\left[G_{v R} \sin \left(\theta_{k}-\delta_{v R}\right)-B_{v R} \cos \left(\theta_{k}-\delta_{v R}\right)\right]
\end{aligned}
$$

Here voltage magnitude $V_{v R}$ and phase angle $\delta_{v R}$ are taken as state variables. 


\subsection{Modelling of UPFC}

UPFC comprises of two voltage source converters(VSCs) one connected in series and the other connected in shunt with the line, sharing a common capacitor. The series converter injects an AC voltage in to the line with controllable magnitude and phase angle in series with the transmission line via a series connected coupling transformer [16]. The shunt converter generate or absorbs reactive power and independently provide compensation for the line. The basic model of UPFC is given in Fig. 3. The equivalent circuit shown in Fig. 4 is used to derive the mathematical model of the controller for the purpose of steady state analysis [16].

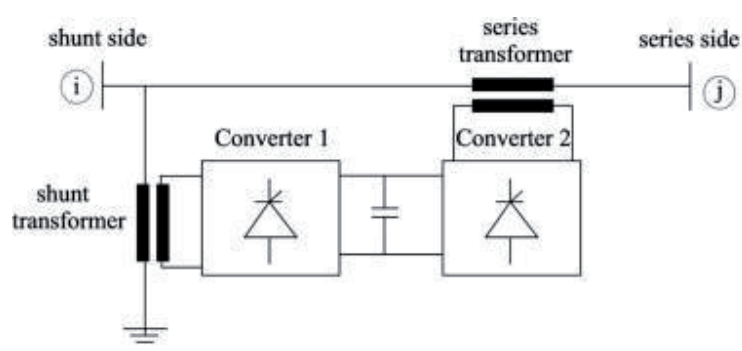

Fig. 3 Unified Power Flow Controller

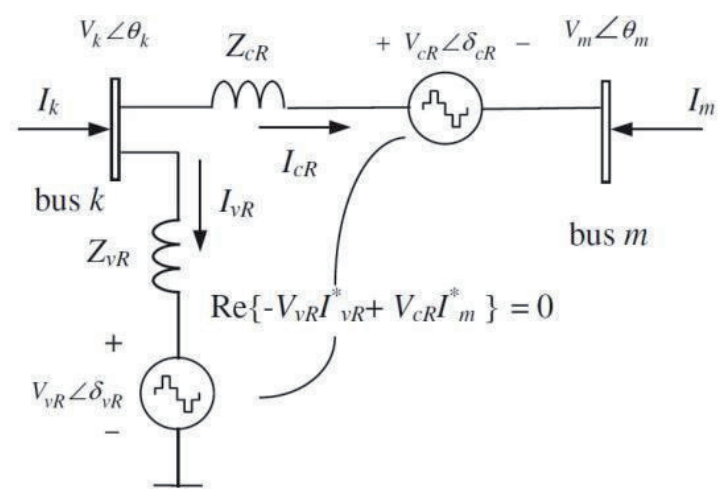

Fig. 4 Equivalent circuit of Unified Power Flow Controller

\subsubsection{Power flow equations of UPFC}

The UPFC voltage source equations are given by [16]

$$
\begin{aligned}
& E_{v r}=V_{v R}\left(\cos \delta_{v R}+j \sin \delta_{v R}\right) \\
& E_{c r}=V_{c R}\left(\cos \delta_{c R}+j \sin \delta_{c R}\right)
\end{aligned}
$$

Let us consider that an UPFC is connected between bus $\mathrm{k}$ and bus m. From Fig. 3 the active and reactive power equations at the converter, bus $\mathrm{k}$ and bus $\mathrm{m}$ are given by [16]

$$
\begin{aligned}
& P_{c R}=V_{c R}^{2} G_{m m}+V_{c R} V_{k}\left[G_{k m} \cos \left(\delta_{c R}-\theta_{k}\right)+B_{k m} \sin \left(\delta_{c R}-\theta_{k}\right)\right] \\
& +V_{c R} V_{m}\left[G_{m m} \cos \left(\delta_{c R}-\theta_{m}\right)+B_{m m} \sin \left(\delta_{c R}-\theta_{m}\right)\right] \\
& Q_{c R}=-V_{c R}^{2} B_{m m}+V_{c R} V_{k}\left[G_{k m} \sin \left(\delta_{c R}-\theta_{k}\right)-B_{k m} \cos \left(\delta_{c R}-\theta_{k}\right)\right] \\
& +V_{c R} V_{m}\left[G_{m m} \sin \left(\delta_{c R}-\theta_{m}\right)-B_{m m} \cos \left(\delta_{c R}-\theta_{m}\right)\right] \\
& P_{c R}=V_{c R}^{2} G_{m m}+V_{c R} V_{k}\left[G_{k m} \cos \left(\delta_{c R}-\theta_{k}\right)+B_{k m} \sin \left(\delta_{c R}-\theta_{k}\right)\right] \\
& +V_{c R} V_{m}\left[G_{m m} \cos \left(\delta_{c R}-\theta_{m}\right)+B_{m m} \sin \left(\delta_{c R}-\theta_{m}\right)\right]
\end{aligned}
$$

$$
\begin{aligned}
& Q_{c R}=-V_{c R}^{2} B_{m m}+V_{c R} V_{k}\left[G_{k m} \sin \left(\delta_{c R}-\theta_{k}\right)-B_{k m} \cos \left(\delta_{c R}-\theta_{k}\right)\right] \\
& +V_{c R} V_{m}\left[G_{m m} \sin \left(\delta_{c R}-\theta_{m}\right)-B_{m m} \cos \left(\delta_{c R}-\theta_{m}\right)\right] \\
& P_{v R}=-V_{v R}^{2} G_{v R}+V_{v R} V_{k}\left[G_{v R} \cos \left(\delta_{v R}-\theta_{k}\right)+B_{v R} \sin \left(\delta_{v R}-\theta_{k}\right)\right] \\
& Q_{v R}=V_{v R}^{2} B_{v R}+V_{v R} V_{k}\left[G_{v R} \sin \left(\delta_{v R}-\theta_{k}\right)-B_{v R} \cos \left(\delta_{v R}-\theta_{k}\right)\right] \\
& \quad P_{k}=V_{k}^{2} G_{k k}+V_{k} V_{m}\left[G_{k m} \cos \left(\theta_{k}-\theta_{m}\right)+B_{k m} \sin \left(\theta_{k}-\theta_{m}\right)\right] \\
& \quad+V_{k} V_{c R}\left[G_{k m} \cos \left(\theta_{k}-\delta_{c R}\right)+B_{k m} \sin \left(\theta_{k}-\delta_{c R}\right)\right] \\
& \quad+V_{k} V_{v R}\left[G_{v R} \cos \left(\theta_{k}-\delta_{v R}\right)+B_{v R} \sin \left(\theta_{k}-\delta_{v R}\right)\right] \\
& Q_{k}=-V_{k}^{2} B_{k k}+V_{k} V_{m}\left[G_{k m} \sin \left(\theta_{k}-\theta_{m}\right)-B_{k m} \cos \left(\theta_{k}-\theta_{m}\right)\right] \\
& +V_{k} V_{c R}\left[G_{k m} \sin \left(\theta_{k}-\delta_{c R}\right)-B_{k m} \cos \left(\theta_{k}-\delta_{c R}\right)\right] \\
& +V_{k} V_{v R}\left[G_{v R} \sin \left(\theta_{k}-\delta_{v R}\right)-B_{v R} \cos \left(\theta_{k}-\delta_{v R}\right)\right] \\
& \quad P_{m}=V_{m}^{2} G_{m m}+V_{m} V_{k}\left[G_{m k} \cos \left(\theta_{m}-\theta_{k}\right)+B_{m k} \sin \left(\theta_{m}-\theta_{k}\right)\right] \\
& +V_{m} V_{c R}\left[G_{m m} \cos \left(\theta_{m}-\delta_{c R}\right)+B_{m m} \sin \left(\theta_{m}-\delta_{c R}\right)\right] \\
& Q_{m}=-V_{m}^{2} B_{m m}+V_{m} V_{k}\left[G_{m k} \sin \left(\theta_{m}-\theta_{k}\right)-B_{m k} \cos \left(\theta_{m}-\theta_{k}\right)\right] \\
& +V_{m} V_{c R}\left[G_{m m} \sin \left(\theta_{m}-\delta_{c R}\right)-B_{m m} \cos \left(\theta_{m}-\delta_{c R}\right)\right]
\end{aligned}
$$

If the converter valves are loss less, then the active power supplied to the shunt converter $P_{v R}$ equals to the active power demanded by the series converter $P_{c R}$ [16].

$$
P_{v R}+P_{c R}=0
$$

\section{Results and Discussion}

The case studies mentioned in Section 1 are carried out without and with FACTS devices on a standard 5 bus system and IEEE 30 bus system. A standard 5 bus system consists of 2 generators, 7 transmission lines and having a demand of 165 MW interconnected to the 5 buses. Similarly in IEEE 30 bus system 6 thermal generators, 41 transmission lines with a connected load of 283.4 MW are interconnected to the 30 buses. The above said demand for the two test systems is considered as the base load. The simulations are performed in Matlab environment. The system configuration used is Intel core i5 processor, with $8 \mathrm{gb}$ ram capacity.

The static models of Static shunt Compensator (STATCOM) and Unified Power Flow Controller (UPFC) are incorporated in to Newton Raphson power flow analysis and their performances are analysed. The parameters such as voltage profile, power flows, real \& reactive power generations and Power loss are observed for the above said cases.

Steps for solving load flow analysis using NR method [19]

1. Specify the bas data, line data and FACTS device data. Formulate the Ybus matrix.

2. Specify the initial voltage the generator buses and load buses. 
3. Now incorporate the FACTS device at the desired location.

4. Calculate the $P$ at PV buses and PQ buses. Calculate $Q$ at PQ buses.

5. Calculate the power mismatches and also calculate the Jacobian matrix elements.

6. Compute the new voltage magnitudes and phase angles until the residuals are less than desired accuracy.

\subsection{Performance analysis of FACTS devices under Base Load condition}

Load flow analysis without FACTS devices is carried out and the voltage magnitudes, phase angles, power loss and power generations in 5 bus system are furnished in column 3 of Table 1 . The given results are treated as base case values of standard 5 bus system. From the table it is observed that the voltages at the load buses $(0.987,0.984,0.971)$ are not in tolerable limits and the power loss is also high (3.64\% of total load).

\subsubsection{Voltage profile improvement with FACTS devices}

FACTS devices absorbs or injects reactive power from/ into the system and maintains the voltage magnitude to the desired level [15]. Improvement of voltage magnitude by incorporating
STATCOM at different locations is analysed for the two test systems and the results are given in Tables 1 and 2 respectively.

For instance, In standard 5 bus test system the STATCOM is incorporated at bus 4 , and it is observed that the voltage magnitude at the bus is improved to 1.00 p.u. (from 0.984 p.u.), by injecting a reactive power of 25.32 MVAr in to the system. It is also observed that the voltage profile of buses 3 and 5 are improved by $1.2 \%$ and $0.6 \%$ from the base case respectively. This shows that the STATCOM has the ability to improve the voltage profile of the nearby buses also. Similarly the performance of STATCOM by incorporating at buses 3 and 5 is analysed and the results are given in Table 1.

A similar case study is performed on IEEE 30 bus system by incorporating STATCOM at buses 21, 22 and 24. For instance, consider STATCOM is placed at bus 21. It is observed that the voltage magnitude at the bus is improved to 1.00 p.u. from a base value of 0.96 p.u. and the voltage at the other buses is also improved. Results are furnished in Table 2. The voltage profile without and with STATCOM at bus 21 is shown in Fig. 5. From the results it is inferred that STATCOM helps in providing a smoother control over a wide range.

UPFC is a combined series-shunt controller which helps in improving both power flows and voltage profile [16].

Table 1 Analysis without and with FATCS devices at various locations

\begin{tabular}{|c|c|c|c|c|c|c|c|}
\hline \multirow{2}{*}{ Parameter } & \multirow{2}{*}{ Bus No } & \multirow{2}{*}{ Base case } & \multicolumn{3}{|c|}{ STATCOM } & \multicolumn{2}{|c|}{ UPFC } \\
\hline & & & at Bus 3 & at Bus 4 & at Bus 5 & in Line $3-4$ & in Line $4-5$ \\
\hline \multirow{5}{*}{$\begin{array}{l}\text { Voltage } \\
\text { Magnitude (p.u.) }\end{array}$} & 1 & 1.06 & 1.06 & 1.06 & 1.06 & 1.06 & 1.06 \\
\hline & 2 & 1.00 & 1.00 & 1.00 & 1.00 & 1.00 & 1.00 \\
\hline & 3 & 0.987 & $1.00(1.31 \%)$ & $0.999(1.2 \%)$ & $0.992(0.5 \%)$ & 1.00 & 0.999 \\
\hline & 4 & 0.984 & $0.994(0.7 \%)$ & $1.00(1.6 \%)$ & $0.991(0.7 \%)$ & 0.987 & 1.00 \\
\hline & 5 & 0.971 & $0.975(0.4 \%)$ & $0.977(0.6 \%)$ & $1.00(2.98 \%)$ & 0.972 & 0.972 \\
\hline \multirow{4}{*}{$\begin{array}{l}\text { Active (MW)/ } \\
\text { Reactive Power } \\
\text { (MVAr) } \\
\text { Generations }\end{array}$} & $P_{G 1}$ & 131.12 & $131.056(-0.05 \%)$ & $131.08(-0.04 \%)$ & $131.18(0.05 \%)$ & 131.13 & 131.093 \\
\hline & $\mathrm{Q}_{\mathrm{G} 1}$ & 90.82 & $85.34(-6.03 \%)$ & $85.51(-5.84 \%)$ & $88.47(-2.59 \%)$ & 85.54 & 85.561 \\
\hline & $\mathrm{P}_{\mathrm{G} 2}$ & 40 & 40 & 40 & 40 & 40.00 & 40.00 \\
\hline & $\mathrm{Q}_{\mathrm{G} 2}$ & -61.59 & $-77.06(25.13 \%)$ & $-81.45(32.25 \%)$ & $-91.42(48.43 \%)$ & -71.60 & -78.09 \\
\hline \multirow{2}{*}{$\begin{array}{l}\text { Active (MW)/ } \\
\text { Reactive Power } \\
\text { (MVAr) Loss }\end{array}$} & $\mathrm{P}_{\text {loss }}$ & 6.122 & $6.092(-1.08 \%)$ & $6.087(-0.57 \%)$ & $6.181(0.96 \%)$ & 6.132 & 6.093 \\
\hline & $\mathrm{Q}_{\text {loss }}$ & -10.77 & $-10.926(-4.49 \%)$ & $-11.231(-4.28 \%)$ & $-10.955(-1.71 \%)$ & -10.909 & -11.117 \\
\hline
\end{tabular}

Table 2 Profile and Power loss with STATCOM in IEEE 30 bus system

\begin{tabular}{|c|c|c|c|c|}
\hline Voltage /Power Loss & Base Case & STATCOM at Bus 21 & STATCOM at Bus 22 & STATCOM at Bus 24 \\
\hline B21 & 0.960 & 1.000 & 0.997 & 0.986 \\
\hline B22 & 0.961 & 0.998 & 1.000 & 0.988 \\
\hline B24 & 0.947 & 0.975 & 0.976 & 1.000 \\
\hline $\mathrm{P}_{\text {loss }}(\mathrm{MW})$ & 18.313 & 17.945 & 17.962 & 17.946 \\
\hline $\mathrm{Q}_{\text {loss }}(\mathrm{MVAr})$ & 59.398 & 55.852 & 55.936 & 56.105 \\
\hline
\end{tabular}


UPFC is placed in two different lines and the voltage profile is compared. When UPFC is placed in line 3-4 the voltage magnitude at bus 3 is increased to 1.00 p.u. and the voltages at buses $4 \& 5$ are also improved. Similarly, When UPFC is placed in line 4-5 the voltage magnitude of bus 4 is improved to 1.00 p.u. and the voltage at the other buses is also improved significantly compared to previous case. The results are furnished in Table 1.

UPFC is placed in line 21-22 of the IEEE 30 bus system and the voltage profile is plotted in Fig. 6. It is observed that the voltage at the bus 21 is improved from 0.96 p.u. to 0.995 p.u. and the voltage at the other buses is also improved significantly. From the above analysis it is inferred that location of FACTS devices plays a key role in improvement of voltage profile.

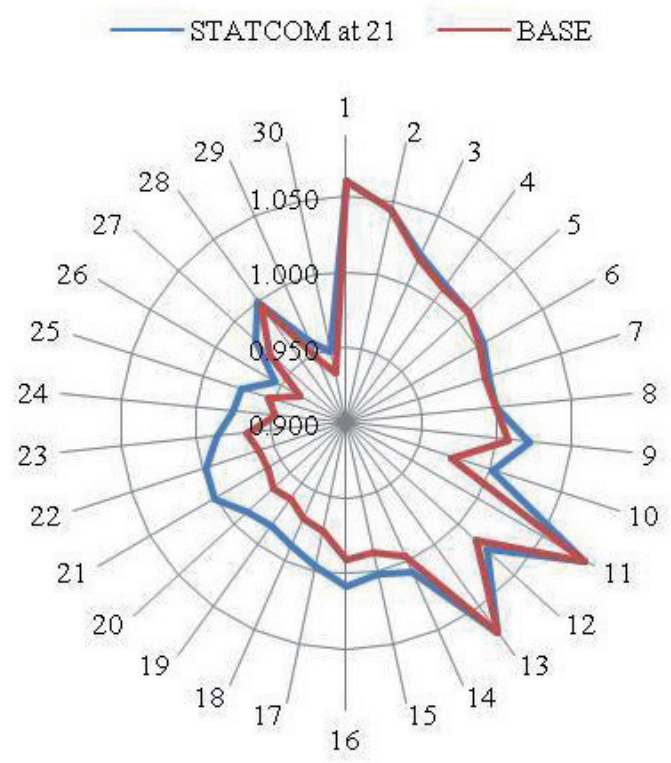

Fig. 5 Voltage profile without and with STATCOM in IEEE 30 bus system

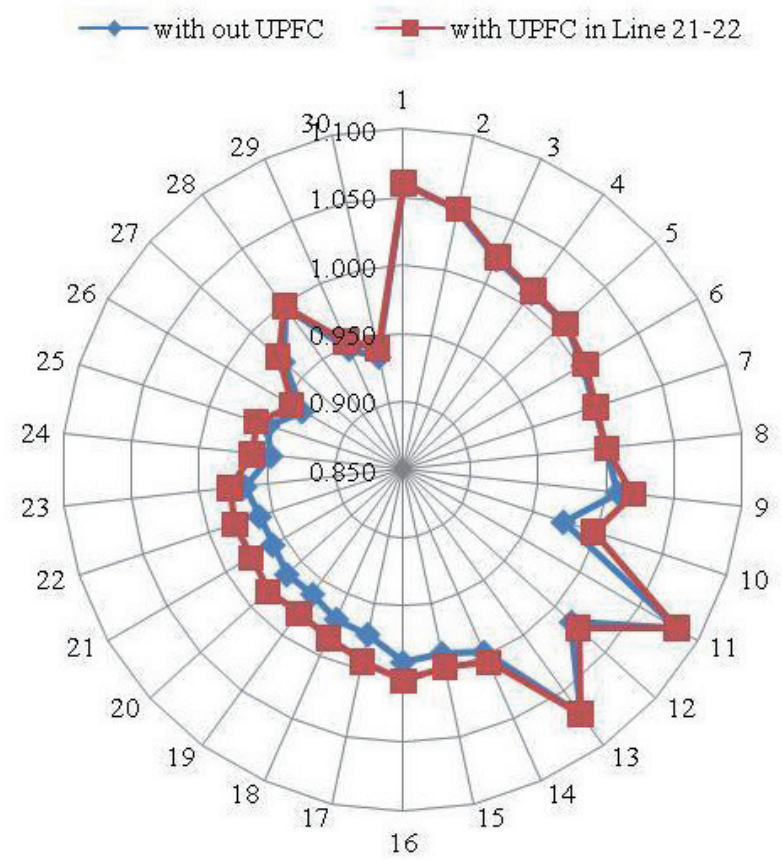

Fig. 6 Voltage profile without and with UPFC in IEEE 30 bus system

\subsubsection{Power Flow Analysis with FACTS devices}

STATCOM is incorporated at various buses and the power flows in the lines are observed. In standard 5 bus test system, when the STATCOM is placed at bus 3 the reactive power carried by lines 1-3 \& 2-3 is reduced and line 3-4 carries more reactive power compared to base case. This is because the STATCOM supplies the reactive power required by the load and reduces reactive power burden on the generators. This is shown in Column 4 of Table 1. It is observed that the generator at the slack bus reduces its generation and the generator at bus 2 absorbs more reactive power compared to base case. Similarly when the STATCOM is placed at buses $4 \& 5$, the power flows and power generations are obtained and given in Table 1 . The active and reactive power loss by incorporating STATCOM at various locations are calculated and shown in Row number 4 of Table 1. When STATCOM is placed at bus 3 the active power loss is reduced by $1.08 \%$ compared to base case and it is increased by $0.96 \%$ when placed at bus 5. It indicates that the losses of the system are reduced only when proper location is chosen. The reactive power loss is reduced in all the cases as the STATCOM supplies the required reactive power and reduces burden on the sources.

The active and reactive power loss when STATCOM is placed at buses 21, 22 and 24 of IEEE 30 bus system are given in Table 2. From the table it is inferred that the losses are reduced significantly when STATCOM is placed at bus 21 .

The active and reactive power flows with UPFC in line 3-4 and line 4-5 are observed by running the load flow. For instance, consider UPFC is placed in line 3-4 and it is observed that the active power flow is increased from 19.38 MW to 29.07 $\mathrm{MW}$ and the reactive power in the line is reduced to 2.0 MVAr from 2.86 MVAr. This shows that UPFC has ability to control both active and reactive powers simultaneously in a line. The power flows in the lines are improved significantly when UPFC is placed in test system.

The active and reactive power losses with UPFC at locations 3-4 and 4-5 are given in Table 1. From the table it is inferred that the active power loss of the system will change accordingly with amount of power to be transferred through a line and also with the location of the FACTS device. For instance, consider the UPFC is placed in line 3-4 and the power flow is increased in the line by $150 \%$ of actual. UPFC controls the power as desired in the line, but the losses are proportionately increased. Similarly when UPFC is placed in line 4-5 the losses are decreased. The reactive power losses are decreased in both the cases with incorporation of UPFC in the line. This shows that with optimal location of FACTS device the losses in the system can be minimized.

The active and reactive power generations with UPFC are also shown in Table 1. UPFC is incorporated in lines 3-4 and 4-5 separately and the analysis is done. It is inferred that there is no significant change in real power generations when UPFC is placed in the lines. But the reactive power generation at the 
slack bus is decreased and the generator at bus 2 absorbs more reactive power compared to base case. This is because the shunt converter of UPFC generates reactive power and reduces burden on the generators. Here the series converter remains inactive.

The active and reactive power loss when UPFC is placed in the lines 21-22 and 24-25 of IEEE 30 bus test system are given in Table 3. It is observed that the power loss is reduced with proper control of power in the lines.

Table 3 Active and Reactive power loss without and with UPFC in IEEE 30 bus system

\begin{tabular}{llll}
\hline Power Loss & Base case & $\begin{array}{l}\text { UPFC in Line } \\
21-22\end{array}$ & $\begin{array}{l}\text { UPFC in Line } \\
24-25\end{array}$ \\
\hline $\mathrm{P}_{\text {loss }}(\mathrm{MW})$ & 18.313 & 18.128 & 18.180 \\
$\mathrm{Q}_{\text {loss }}(\mathrm{MVAr})$ & 59.398 & 56.793 & 57.931 \\
\hline
\end{tabular}

\subsection{Operating Modes of FACTS devices corresponding to specified voltage}

The main purpose of the shunt converter is to maintain the desired voltage magnitude at the bus at which it is connected by injecting (absorbing) reactive power in to the bus. If the converter voltage magnitude is less than the source voltage then the converter will be in inductive mode. In this mode the converter absorbs reactive power from the system. If the converter voltage is greater than source voltage then it will be in capacitive mode and it injects reactive power into the system.

Depending upon the voltage to be maintained at a bus the STATCOM generates (or absorbs) reactive power into the system. Here an analysis is carried out to differentiate the modes of operation with respect to specified voltage. The STATCOM is placed at bus 4 and the specified voltage $V_{\text {spec }}$ is varied from a value less than base voltage to a value above base voltage. It is observed that if the STATCOM has to maintain a voltage less than base case, it operates in inductive mode (Ind) and if the device has to maintain a value greater than base case it operates in capacitive mode (Cap). When system voltage is to be maintained at base value the STATCOM stays inoperative (Inop). If the source voltage is less than the converter voltage $\left(\mathrm{V}_{\mathrm{vr}}\right)$ then the STATCOM operates in inductive mode and if the source voltage is greater than the converter voltage $\left(\mathrm{V}_{\mathrm{vr}}\right)$ then the STATCOM operates in capacitive mode. The obtained results are furnished in column 2 of Table 4. STATCOM is also placed at buses $3 \& 5$ and the characteristics between Reactive power generated (absorbed) by STATCOM $\left(Q_{s}\right)$ vs. specified voltage $\left(\mathrm{V}_{\mathrm{sp}}\right)$ are plotted in Fig. 7. Another graph between converter voltage $\left(\mathrm{V}_{\mathrm{vr}}\right)$ vs. specified voltage $\left(\mathrm{V}_{\mathrm{sp}}\right)$ is shown in Fig. 8.

In IEEE 30 bus test system the STATCOM is placed at bus 21 and the characteristics of specified voltage $\left(\mathrm{V}_{\mathrm{sp}}\right)$ vs. Reactive power $\left(\mathrm{Q}_{\mathrm{s}}\right)$ and converter voltage $\left(\mathrm{V}_{\mathrm{vr}}\right)$ are given in column 3 of Table 4 . The characteristics of specified voltage $\left(\mathrm{V}_{\mathrm{sp}}\right)$ vs. Reactive power $\left(Q_{s}\right)$ when STATCOM is placed at buses 21 and 24 are plotted in Fig. 7. Similarly the plot between specified voltage $\left(\mathrm{V}_{\mathrm{sp}}\right)$ vs. converter voltage $\left(\mathrm{V}_{\mathrm{vr}}\right)$ is shown in Fig. 8. The inductive and capacitive modes of STATCOM are clearly observed from the figures. The relation between source voltage and converter voltage with change in modes is also observed. In inductive mode converter voltage is less than the specified voltage and in capacitive mode the converter voltage is greater than specified voltage.

In the designed UPFC model, the shunt converter helps in providing reactive power support and thus maintains the voltage profile at desired level. The performance of shunt converter for UPFC is analysed by placing in line 3-4 of standard 5 bus test system. Here it is observed that converter voltage changes corresponds to specified voltage and its operation in both inductive and capacitive modes are observed. The obtained results are given in Table 4.

Now UPFC is placed in line 21-22 of IEEE 30 bus system and the operating modes of shunt converter are given in column 4 of Table 4 . It is observed that if the voltage specified $\left(V_{s p}\right)$ is less than the base voltage then the converter absorbs reactive power from the system. Here the converter voltage $\left(\mathrm{V}_{\mathrm{vr}}\right)$ is less than the voltage specified. If the voltage specified is greater than the base voltage the converter injects reactive power in to the system. Here converter voltage is greater than the voltage specified is observed.

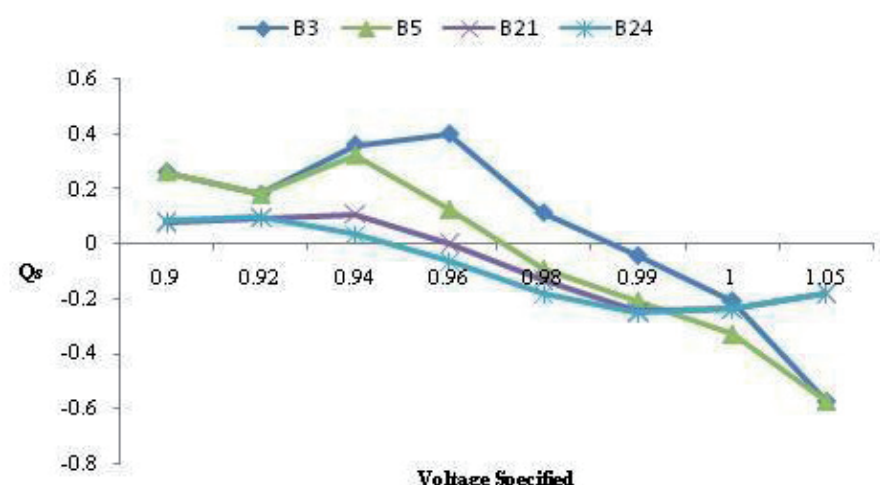

Fig. 7 Operating modes of STATCOM when placed at various buses

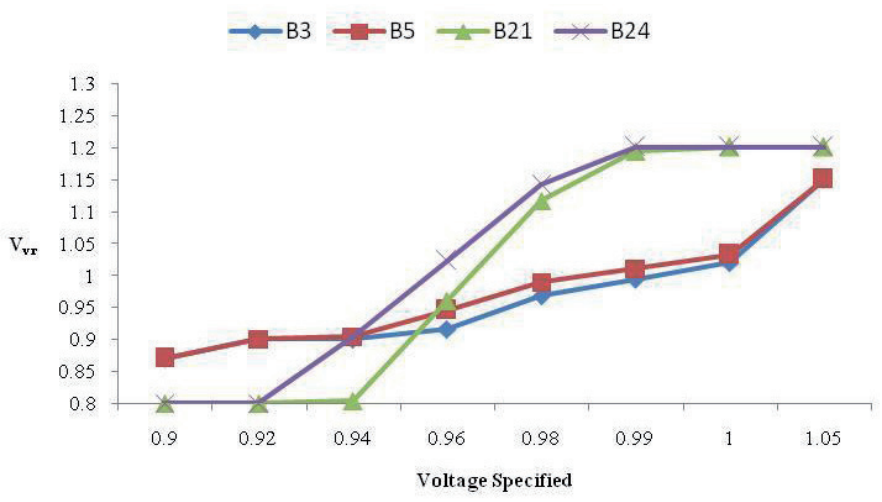

Fig. 8 Converter voltage vs. Specified Voltage of STATCOM when placed at various buses 
Table 4 Operating modes of STATCOM corresponding to specified voltage in two test systems

\begin{tabular}{|c|c|c|c|c|c|c|c|c|c|c|c|c|}
\hline \multirow{3}{*}{$\begin{array}{l}\text { Specified } \\
\text { Voltage (p.u.) }\end{array}$} & \multicolumn{6}{|c|}{ STATCOM } & \multicolumn{6}{|c|}{ UPFC } \\
\hline & \multicolumn{3}{|c|}{ Standard 5 bus system } & \multicolumn{3}{|c|}{ IEEE 30 bus system } & \multicolumn{3}{|c|}{ Standard 5 bus system } & \multicolumn{3}{|c|}{ IEEE 30 bus system } \\
\hline & $\mathrm{Q}_{\mathrm{S}}$ & $\mathrm{V}_{\mathrm{vr}}$ (p.u.) & Mode & $\mathrm{Q}_{\mathrm{S}}(\mathrm{MVAr})$ & $\mathrm{V}_{\mathrm{vr}}$ (p.u.) & Mode & $\mathrm{Q}_{\mathrm{sh}}$ & Vvr & Mode & $\mathrm{Q}_{\mathrm{sh}}$ & Vvr & Mode \\
\hline 0.9 & 0.261 & 0.87 & Ind & 0.08 & 0.800 & Ind & -0.621 & 0.824 & Ind & -0.227 & 0.87 & Ind \\
\hline 0.92 & 0.18 & 0.9 & Ind & 0.096 & 0.800 & Ind & -0.491 & 0.863 & Ind & -0.150 & 0.90 & Ind \\
\hline 0.94 & 0.36 & 0.9 & Ind & 0.1072 & 0.8042 & Ind & -0.347 & 0.901 & Ind & -0.067 & 0.93 & Ind \\
\hline 0.96 & 0.3996 & 0.916 & Ind & 0.000 & 0.960 & Inop & -0.187 & 0.940 & Ind & 0.0213 & 0.96 & Cap \\
\hline 0.98 & 0.1125 & 0.968 & Ind & -0.132 & 1.116 & Cap & -0.013 & 0978 & Ind & 0.1161 & 0.99 & Cap \\
\hline 0.99 & -0.043 & 0.994 & Cap & -0.244 & 1.194 & Cap & 0.0798 & 0.998 & Cap & 0.1657 & 1.00 & Cap \\
\hline 1.0 & -0.208 & 1.02 & Cap & -0.24 & 1.200 & Cap & 0.1764 & 1.017 & Cap & 0.2198 & 1.02 & Cap \\
\hline 1.05 & -0.575 & 1.15 & Cap & -0.18 & 1.200 & Cap & 0.7167 & 1.114 & Cap & 0.4947 & 1.09 & Cap \\
\hline
\end{tabular}

\subsection{Performance analysis of FACTS devices under increased loading condition}

As the increasing demand on existing power system is a most common issue, a case study by increasing the load at a particular bus to $150 \%$ of base case is carried out on a standard 5 bus system without and with STATCOM. Here the effectiveness of the above said device is observed in terms of voltage profile and power loss.

\subsubsection{Voltage profile improvement with STATCOM}

In this case, the load at bus 3 is increased to $150 \%$ of the actual value and the load flow analysis is done. It is observed that the voltages at the buses are still reduced compared to the base case. Now STATCOM is incorporated at bus 3 and the analysis is repeated. It is seen that the voltage at bus 3 is raised to 1.00 p.u. and the voltages at the other load buses $4 \& 5$ are increased by $1.74 \%$ and $0.61 \%$ respectively. This shows that if the STATCOM is properly designed to meet the requirements it works effectively even under heavy load conditions. To test the effectiveness of the device, similar analysis has been carried out at the other load buses 4 and 5 by incorporating STATCOM at these locations. The analysis is given in column 3 of Table 5 .

\subsubsection{Power Flow Analysis with STATCOM}

In the analysis as said above it is observed commonly in all the cases that the power loss is increased significantly depending on the loading at the bus. When STATCOM is placed at bus 3 the active power loss is reduced by $2.5 \%$. Conversely when the STATCOM is placed at bus 5 the power loss is increased to $0.73 \%$. The total reactive power loss is decreased in all the locations with STATCOM. Consider the case when STATCOM is placed at bus 3, the reactive power loss is reduced by $16.8 \%$ where as it is reduced by $15.47 \%$ when placed at bus 3 . This shows that the location of FACTS device has much significance in reducing the system losses. The numerical with respect to this analysis are given in column 3 of Table 5 .

\subsection{Analysis of FACTS devices under single line contingency}

Contingency analysis is very important step in planning studies for a power system engineer [17]. It is essential to predict the heavy loads and emergencies which occur in a power system such that suitable action can be taken in predefined time. This analysis is carried out on the two test systems namely standard 5 bus system and IEEE 30 bus system, without and with FACTS devices.

Table 5 Analysis without and with STATCOM for various scenarios in standard 5 bus test system

\begin{tabular}{|c|c|c|c|c|c|c|c|c|c|}
\hline \multirow{3}{*}{$\begin{array}{l}\text { Voltage / } \\
\text { Power Loss }\end{array}$} & \multirow{3}{*}{$\begin{array}{l}\text { Base } \\
\text { case }\end{array}$} & \multicolumn{4}{|c|}{ Voltage profile and Power loss with increased loading } & \multicolumn{4}{|c|}{$\begin{array}{l}\text { Voltage profile and Power loss under single } \\
\text { line contingency }\end{array}$} \\
\hline & & \multirow{2}{*}{$\begin{array}{l}\text { Without STATCOM } \\
\text { at Bus } 3\end{array}$} & \multirow{2}{*}{$\begin{array}{l}\text { With STATCOM } \\
\text { at Bus } 3\end{array}$} & \multirow{2}{*}{$\begin{array}{l}\text { Without STATCOM } \\
\text { at Bus } 5\end{array}$} & \multirow{2}{*}{$\begin{array}{l}\text { With STATCOM } \\
\text { at Bus } 5\end{array}$} & \multirow{2}{*}{$\begin{array}{l}\text { Without } \\
\text { STATCOM }\end{array}$} & \multicolumn{3}{|c|}{ With STATCOM } \\
\hline & & & & & & & at Bus 3 & at Bus 4 & at Bus 5 \\
\hline V1 & 1.06 & 1.06 & 1.06 & 1.06 & 1.06 & 1.06 & 1.06 & 1.06 & 1.06 \\
\hline $\mathrm{V} 2$ & 1.00 & 1.00 & 1.00 & 1.00 & 1.00 & 1.00 & 1.00 & 1.00 & 1.00 \\
\hline V3 & 0.987 & 0.981 & 1.00 & 0.983 & $0.991(0.81 \%)$ & 0.977 & 1.00 & 0.999 & 0.987 \\
\hline V4 & 0.984 & 0.977 & $0.994(1.74 \%)$ & 0.979 & $0.990(1.12 \%)$ & 0.972 & 0.993 & 1.00 & 0.984 \\
\hline V5 & 0.971 & 0.969 & $0.975(0.61 \%)$ & 0.955 & 1.00 & 0.967 & 0.974 & 0.976 & 1.00 \\
\hline $\mathrm{P}_{\text {loss }}(\mathrm{MW})$ & 6.122 & 7.698 & $7.540(-2.5 \%)$ & 8.865 & $8.930(0.73 \%)$ & 7.036 & 6.886 & 6.929 & 7.056 \\
\hline $\mathrm{Q}_{\text {loss }}(\mathrm{MVAr})$ & -10.77 & -5.821 & $-6.799(-16.8 \%)$ & -2.334 & $-2.695(-15.47 \%)$ & -3.876 & -4.768 & -4.692 & -4.262 \\
\hline
\end{tabular}




\subsubsection{Voltage profile improvement with FACTS devices}

Line 2-4 is removed and the system turns to contingency state. Now the power flow analysis is done and it is observed that the voltages at the buses falls under desirable limits. To overcome this STATCOM is incorporated at different load buses and the performance is observed. Under these critical circumstances also STATCOM outperforms its ability in improving the voltage profile. The analysis is tabulated in Column 4 of Table 5.

During the above said contingency the analysis is made with incorporation of UPFC in line 3-4. As said above the voltages are below desirable limits when test system is under contingency. After the incorporation of UPFC the voltages are improved significantly and brought to desirable limits. The analysis with out and with UPFC is given in Table 6.

\subsubsection{Power Flow Analysis with FACTS devices}

Under contingency the STATCOM is incorporated at different load buses and the power flows are observed. The power loss when STATCOM is incorporated at bus 3 is observed as lowest compared to other two locations. So this signifies the importance of choosing optimal location of FACTS device with respect to test conditions. The numerical are shown in column 4 of Table 5 .

During contingency line 2-5 is overloaded and it carries $62.73 \mathrm{MW}$ which is above the desirable limit. It is also observed that lines 3-4 and 4-5 are operating under the flow limit. So by incorporating UPFC in line 3-4 the power flows through the lines are controlled and are maintained in acceptable limits. This analysis is given in Table 6 .
Similar analysis is conducted on IEEE 30 bus test system by incorporating UPFC in a suitable line. Contingency is obtained in the system by removing line 4-12. Due to this power flow in lines 2-6 and 4-6 violates the flow limit. Now UPFC is placed in two different locations and performance is tested. UPFC is placed in line 4-6 and the power flow is reduced to $89 \mathrm{MW}$, but the other line 2-6 still violates the flow limit. Now UPFC is incorporated in line 5-7 and the power flow through the line is controlled. By doing this we achieve all lines operating under flow limit. It is also observed that the Power loss in the lines increases with contingency. This analysis in terms of numerical is shown in Table 7.

\subsubsection{Recommendations on FACTS devices Applications}

Selection of FACTS devices is made based on application, location and cost of installation. FACTS devices helps in improving voltage profile, minimizing losses, increase power flows and also provide reactive power support. STATCOM and UPFC can help in improving voltage profile. But if the requirement confines to only voltage profile STATCOM is advantageous due to its low cost and less complexity than UPFC. If the application involves multiple functions like controlling real power, reactive power, phase angle and voltage profile then UPFC is best suited. Cost comparison of various FACTS controllers is given in [18]. The cost for installing an STATCOM is $50 \$ / \mathrm{kVAR}$ and the cost of UPFC is almost double the cost of STATCOM as it involves two converters. Even though the installation costs of FACTS devices is costlier profits can be achieved after a certain period.

Table 6 Analysis without and with UPFC under single line contingency

\begin{tabular}{|c|c|c|c|c|}
\hline \multirow{2}{*}{ Parameter } & \multirow{2}{*}{ Bus / Line No } & \multirow{2}{*}{ Base case } & \multicolumn{2}{|c|}{ Contingency in Line 2-4 } \\
\hline & & & Without UPFC & UPFC in Line $3-4$ \\
\hline \multirow{5}{*}{$\begin{array}{l}\text { Voltage Magnitude } \\
\text { (p.u.) }\end{array}$} & 1 & 1.06 & 1.06 & 1.06 \\
\hline & 2 & 1.00 & 1.00 & 1.00 \\
\hline & 3 & 0.987 & 0.977 & 1.00 \\
\hline & 4 & 0.984 & 0.972 & 0.974 \\
\hline & 5 & 0.971 & 0.967 & 0.968 \\
\hline \multirow{7}{*}{$\begin{array}{l}\text { Actual Power Flow } \\
\text { (MW) }\end{array}$} & $1--2$ & 89.33 & 82.10 & 79.48 \\
\hline & $1--3$ & 41.79 & 49.92 & 52.46 \\
\hline & $2--3$ & 24.47 & 37.04 & 40.66 \\
\hline & $2--4$ & 27.71 & -- & -- \\
\hline & $2--5$ & 54.65 & 62.73 & 56.54 \\
\hline & $3--4$ & 19.38 & 39.03 & 45.00 \\
\hline & $4--5$ & 6.59 & -1.127 & 4.78 \\
\hline Active Power Loss & - & 6.12 & 7.04 & 6.95 \\
\hline
\end{tabular}


Table 7 Power flows without and with UPFC under contingency in IEEE 30 bus system

\begin{tabular}{|c|c|c|c|c|c|}
\hline \multirow{2}{*}{ S.No } & \multirow{2}{*}{ Line } & \multicolumn{3}{|c|}{ Power Flow (MW) with Line 4--12 removed } & \multirow{2}{*}{$\begin{array}{l}\text { Flow Limit } \\
\text { (MW) }\end{array}$} \\
\hline & & Without UPFC & UPFC in 4--6 & UPFC in 5--7 & \\
\hline 1 & $1--2$ & 183.707 & 192.410 & 193.550 & 130 \\
\hline 2 & $1--3$ & 81.490 & 73.550 & 73.369 & 130 \\
\hline 3 & $2--4$ & 42.152 & 29.719 & 29.025 & 65 \\
\hline 4 & $3--4$ & 76.390 & 68.944 & 68.777 & 130 \\
\hline 5 & $2--5$ & 86.279 & 92.611 & 126.399 & 130 \\
\hline 6 & $2--6$ & 67.709 & 81.938 & 49.906 & 65 \\
\hline 7 & $4--6$ & 109.242 & 89.944 & 89.114 & 90 \\
\hline 8 & $5--7$ & -11.148 & -5.304 & 25.289 & 70 \\
\hline 9 & 6--7 & 34.465 & 28.430 & -2.191 & 130 \\
\hline 10 & 6--8 & 31.505 & 31.448 & 31.429 & 32 \\
\hline 11 & 6--9 & 51.953 & 52.231 & 52.207 & 65 \\
\hline 12 & $6--10$ & 28.922 & 29.111 & 29.106 & 32 \\
\hline 13 & 9--11 & 0.000 & 0.000 & 0.000 & 65 \\
\hline 14 & 9--10 & 51.953 & 52.231 & 52.207 & 65 \\
\hline 15 & 4--12 & -- & -- & -- & - \\
\hline 16 & $12--13$ & 0.000 & 0.000 & 0.000 & 65 \\
\hline 17 & $12--14$ & 3.524 & 3.674 & 3.669 & 32 \\
\hline 18 & $12--15$ & -1.179 & -1.161 & -1.163 & 32 \\
\hline 19 & $12--16$ & -13.546 & -13.713 & -13.707 & 32 \\
\hline 20 & $14--15$ & -2.733 & -2.594 & -2.598 & 16 \\
\hline 21 & $16--17$ & -17.387 & -17.632 & -17.622 & 16 \\
\hline 22 & $15--18$ & -5.079 & -5.095 & -5.093 & 16 \\
\hline 23 & $18--19$ & -8.366 & -8.409 & -8.406 & 16 \\
\hline 24 & 19--20 & -17.940 & -17.997 & -17.993 & 32 \\
\hline 25 & $10--20$ & 20.694 & 20.748 & 20.744 & 32 \\
\hline 26 & $10--17$ & 27.002 & 27.314 & 27.300 & 32 \\
\hline 27 & $10--21$ & 18.189 & 18.251 & 18.244 & 32 \\
\hline 28 & $10--22$ & 9.190 & 9.230 & 9.225 & 32 \\
\hline 29 & $21--22$ & 0.522 & 0.590 & 0.584 & 32 \\
\hline 30 & $15--23$ & -7.277 & -7.180 & -7.185 & 16 \\
\hline 31 & $22--24$ & 9.626 & 9.737 & 9.727 & 16 \\
\hline 32 & $23--24$ & -10.658 & -10.599 & -10.603 & 16 \\
\hline 33 & $24--25$ & -10.151 & -10.015 & -10.027 & 16 \\
\hline 34 & $25--26$ & 3.552 & 3.551 & 3.551 & 16 \\
\hline 35 & $25--27$ & -13.931 & -13.791 & -13.803 & 16 \\
\hline 36 & $28--27$ & 27.487 & 27.332 & 27.343 & 65 \\
\hline 37 & $27--29$ & 6.206 & 6.204 & 6.204 & 16 \\
\hline 38 & $27--30$ & 7.112 & 7.110 & 7.110 & 16 \\
\hline 39 & 29--30 & 3.709 & 3.708 & 3.708 & 16 \\
\hline 40 & $8--28$ & 1.373 & 1.322 & 1.308 & 32 \\
\hline 41 & 6--28 & 26.241 & 26.133 & 26.157 & 32 \\
\hline Power Loss & & 21.790 & 22.560 & 23.519 & - \\
\hline
\end{tabular}




\section{Conclusion}

This paper emphasizes the effects of incorporating STATCOM and UPFC in the power transmission network in terms of improvement of power flows, voltage profile and reduction in losses. The analysis is carried out on a benchmark 5 bus system and IEEE 30 bus system. With the incorporation of FACTS devices the lines can be operated near the thermal limits, voltage profile at the buses are improved and the power losses are reduced. During over load at the buses, The voltage profile of the buses are maintained at the operating limits even at over loading conditions. Even under single line contingency by incorporating UPFC in a suitable line, the power flows are controlled and are within flow limits. This analysis shows that with proper choice and optimal location of FACTS devices the power flows can be controlled in a desired manner.

\section{Acknowledgements}

The authors thank the management of VIT University, Vellore, India for providing necessary facilities and encouragement to carry out this work.

\section{References}

[1] Alamelu, S., Baskar, S., Babulal, C. K., Jeyadevi, S. "Optimal Siting and Sizing of UPFC Using Evolutionary Algorithms." International Journal of Electrical Power \& Energy Systems. 69, pp. 222-231. DOI: 10.1016/j.ijepes.2014.12.081

[2] Kundur, P., Paserba, J., Ajjarapu, V., Andersson, G., Bose, A., Canizares, C., Vittal, V. "Definition and classification of power system stability IEEE/CIGRE joint task force on stability terms and definitions." IEEE Transactions on Power Systems. 19(3), pp. 1387-1401. 2004. DOI: $10.1109 /$ tpwrs.2004.825981

[3] Ajjarapu, V., Christy, C. "The continuation power flow: a tool for steady state voltage stability analysis." IEEE Transactions on Power Systems. 7(1), pp. 416-423. 1992. DOI: 10.1109/pica.1991.160593

[4] Hingorani, N. G., Gyugyi, L. "Understanding FACTS: concepts and technology of flexible AC transmission systems." Wiley-IEEE Press, 2000. DOI: $10.1109 / 9780470546802$

[5] Venkateswara Rao, B., Nagesh Kumar, G. V. "Optimal power flow by BAT search algorithm for generation reallocation with unified power flow controller." International Journal of Electrical Power \& Energy Systems. 68, pp. 81-88. 2015. DOI: 10.1016/j.ijepes.2014.12.057

[6] Bhattacharyya, B., Gupta, V. K., Kumar, S. "UPFC with series and shunt FACTS controllers for the economic operation of a power system." Ain Shams Engineering Journal. 5(3), pp. 775-787. 2014.

DOI: 10.1016/j.asej.2014.03.013

[7] Tarafdar Hagh, M., Sharifian, M. B. B., Galvani, S. "Impact of SSSC and STATCOM on power system predictability." International Journal of Electrical Power \& Energy Systems. 56, pp. 159-167. 2014. DOI: 10.1016/j.ijepes.2013.11.025

[8] Kamel, S., Jurado, F., Peças Lopes, J. A. "Comparison of various UPFC models for power flow control." Electric Power Systems Research. 121, pp. 243-251. 2015. DOI: 10.1016/j.epsr.2014.11.001

[9] Noroozian, M., Angquist, L., Ghandhari, M., Andersson, G. "Use of UPFC for optimal power flow control." IEEE Transactions on Power Delivery. 12(4), pp. 1629-1634. 1997. DOI: 10.1109/61.634183
[10] Nabavi-Niaki, A., Iravani, M. R. "Steady-state and dynamic models of unified power flow controller (UPFC) for power system studies." IEEE Transactions on Power Systems. 11(4), pp. 1937-1943. 1996. DOI: $10.1109 / 59.544667$

[11] Fuerte-Esquivel, C. R., Acha, E. "Newton-Raphson algorithm for the reliable solution of large power networks with embedded FACTS devices." IEE Proceedings- Generation, Transmission and Distribution. 143(5), 1996. DOI: 10.1049/ip-gtd:19960531

[12] Fuerte-Esquivel, C. R., Acha, E. "Unified power flow controller: a critical comparison of Newton-Raphson UPFC algorithms in power flow studies." IEE Proceedings-Generation, Transmission and Distribution. 144(5), pp. 437-444. 1997. DOI: 10.1049/ip-gtd:19971385

[13] Castro, L. M., Acha, E., Fuerte-Esquivel, C. R. "A novel STATCOM model for dynamic power system simulations." IEEE Transactions on Power Systems. 28(3), pp. 3145-3154. 2013. DOI: 10.1109/tpwrs.2013.2255319

[14] Kazemtabrizi, B., Acha, E. "An Advanced STATCOM Model for Optimal Power Flows Using Newton's Method." IEEE Transactions on Power Systems. 29(2), pp. 514-525. 2014. DOI: 10.1109/tpwrs.2013.2287914

[15] Sreejith, S., Simon, S. P., Selvan, M. P. "Analysis of FACTS devices on Security Constrained Unit Commitment problem." International Journal of Electrical Power \& Energy Systems. 66, pp. 280-293. 2015. DOI: 10.1016/j.ijepes.2014.10.049

[16] Sreejith, S., Simon, S. P. "Cost benefit analysis on SVC and UPFC in a dynamic economic dispatch problem." International Journal of Energy Sector Management. 8(3), pp. 395-428. 2014. DOI: 10.1108/ijesm-05-2013-0010

[17] Wangdee, W., Li, W., Billinton, R. "Locational transmission capacity reserve determination using system well-being analysis." Electric Power Systems Research. 119, pp. 329-336. 2015. DOI: 10.1016/j.epsr.2014.08.012

[18] Mathur, R. M., Varma, R. K. "Thyristor-based FACTS controllers for electrical transmission systems." John Wiley \& Sons, 2002. DOI: 10.1109/9780470546680

[19] Acha, E., Fuerte-Esquivel, C. R., Ambriz-Perez, H., Angeles-Camacho, C. "FACTS: modelling and simulation in power networks." John Wiley \& Sons, 2004. DOI: 10.1002/0470020164

\section{Appendix}

a) STATCOM Parameters

Inductive Reactance of STATCOM $=10 \Omega$

Target Voltage $=1$ p.u.

Initial value of the source voltage $=1$ p.u.

Initial angle of the source voltage $=0^{\circ}$.

Minimum limit of source voltage $=0.9$ p.u.

maximum limit of source voltage $=1.1$ p.u.

b) UPFC Parameters

Inductive reactance of shunt converter $=0.1 \Omega$

Inductive reactance of series converter $=0.1 \Omega$

Initial voltage of series source $=0.04$ p.u.

Initial angle of series source $=0.0^{\circ}$

Initial voltage of shunt source $=1.0$ p.u.

Initial angle of shunt source $=0.0^{\circ}$.

Minimum voltage limit of series voltage source $=0.001$ p.u

Maximum voltage limit of series voltage source $=0.2$ p.u.

Minimum voltage limit of shunt voltage source $=0.9$ p.u. 